\title{
Chlamydia: Possible Mechanisms of the Long Term Complications
}

\author{
Teoman Zafer Apan \\ Department of Microbiology and Clinical Microbiology \\ Kırkkkale University Faculty of Medicine \\ Turkey
}

\section{Introduction}

Chlamydia an insidious intracellular pathogen implicated in various diseases by increasing inflammation and microbial byproducts. Chronic infection may be observed with major types of causative organism initiated disease on ocular, sinopulmonary and reproductive tract.

Chlamydia trachomatis is one of the infectious cause of ocular disease that is endemic in the regions with limited sanitary resources. The infection may start on eye lids and progress to trichiasis, keratoconjunctivitis and corneal opacity, that eventually lead to vision loss. The chronic infection of the same microorganism in female reproductive system may be associated with pelvic inflammatory disease, infertility, ectopic pregnancy and is proposed to induce ovarian cancer by chronic tubal inflammation. The causative microorganism is also demonstrated to be one of the infectious sources of male infertility. Chlamydia pneumonia, the other serotype of the microorganism, which is capable of pulmonary infection, has been demonstrated to induce nasal polyps, asthma in pediatric and adult population.

Increasing body of evidence indicates that there is an association between chlamydial infection with atherosclerosis and serious related outcomes. Inflammation induced by peroxy-lipid molecules, heat shock protein 60 (HSP 60) and facilitation of the endothelial foam cell formations are the proposed mechanisms.

Interesting findings in several investigations indicate possible association between rheumatoid disease, systemic vasculitis, and certain neurobehavioral diseases such as Alzheimer's disease, multipl sclerosis, seronegative spondylarthritis and Behçet disease and Chlamydia.

Chlamydia is an obligatory intra-cytoplasmal gram negative pathogen that requires invading moist epithelial barriers of conjunctiva, sino-bronchial three, and reproductive tract for infection. The organism is capable of chronic infection by modulating host defense, dormancy or by microbial products. Disease could be occur through direct contamination from infected host with touch or dropouts of cough, infected materials or with fly vectors. 


\subsection{Ocular complications}

Trachoma is a keratoconjunctivitis caused by ocular infection of C. trachomatis. Serotypes A, $\mathrm{B}, \mathrm{Ba}$ and $\mathrm{C}$ are considered to be responsible for disease in corneal epithelium to initiate the disease. The latent phase of the disease takes about 4-7 days. Reinfection after initial clearance of the organism may occur to clinical signs of the disease. The neonatal form of disease also could occur during labor with vaginal serotypes (D and K). Disease is more common in lower socioeconomic status, and close living with family members and limited access to the clear water resources are indicated as other predisposing factors. Trachoma starts on tarsal conjonctiva of the eyelids, progresses to cause trichitis and entropion. Disease may cause blindness, advancing to the cornea to cause opacity. Trachoma is considered as the primary infectious cause of blindness (Wright, 2007). The global burden of the disease has been calculated to reach about 8 billion US dollars including disability induced loss of work years, payment for caregivers. Active or early disease which is common in the childhood that observed as chronic follicular conjunctivitis, and late cicatricial form results of the recurrent inflammation of the infection which leads to corneal opacity are the clinical features of trachoma. World Health Organization in collaboration with other organizations was initiated to decrease the severe outcomes and disease activity. The program which includes surgery for trichiasis, antibiotic therapy for active disease, face cleaning or personal hygiene and environmental improvements (SAFE) was constituted in 1998 that planned to eliminate these complications at 2020 (Burton, 2007). Convincingly, in a study conducted in the endemic region for trachoma after mass treatment with azithromycin or doxicyclin for C. trachomatis, there was no resistance to the antimicrobial treatment (Hong, et al. 2009). Surgical treatment for trichiasis, a late complication of trachoma shows promising results, but requires to be continued with scheduled programs (Burton et al., 2005a). The severity of the ocular pathology in general, influences the duration of the disease that remedy for early intervention in the rural areas such as observed in Ethiopia (Melese et al, 2005). On the other hand, azithromycin treatment after surgery for controlling the relapses has not been changed the outcome (Burton et al, 2005b).

Holland et al. demonstrated that the presence of major outer membrane protein to cytotoxic $\mathrm{T}$ lymphocytes that specific to the $C$. trachomatis is associated with the current ocular disease with longer duration, but neither indicates estimated load of infection nor leads to presume the course of the disease (Holland et al., 2006). Repeated infections of Chlamydia may lead to expression of heat shock proteins (HSP), which closely react with human HSP 60 and are suggested to trigger autoimmune-directed inflammation, which is thought to play role in the pathogenesis of trachoma (Morrison et al., 1989).

In a study based on repeated examination of eyes performed in Australia indicates that $C$. pneumoniae infection was considered as an independent or additional risk factor for agerelated macular degeneration possibly by inducing chronic inflammatory reaction (Robman et al., 2005). C. pneumoniae has also been demonstrated to induce chorioidal neovascularization by inducing Toll-like receptor 2 in an experimental model indicates a risk factor for age related macular degeneration (Fujimoto et al., 2010).

Ocular adnexial lymhomas constitutes the subgroup of non-hodgkin lymphomas originating from lymphoid tissue of mucosal layer. The association between C. psittaci with 
ocular lymphoma was first determined in a study subjecting Italian patients (Ferreri et al., 2004). C. psittaci was also indicated as a possible cause with a varying rate of geographical distribution (Chanudet et al., 2006). However, several studies failed to demonstrate an association between ocular malignancy with Chlamydiae (Yakushijin et al., 2007).

\subsection{Chlamydia and genitourinary tract}

Chlamydia trachomatis is able to infect urogenital tract and is one of the most common sexually transmitted diseases in the Western world (Ward, 1995). Other serotypes including L1, L2, L2a and L3 are also capable of infecting monocytes to cause systemic disease called lympogranulomavenereum (Mabey \& Peeling, 2002). The genital serovars of Chlamydiae are able to migrate to the upper genital tract to induce quiescent infection, which is one of the infectious causes of fallopian tube occlusion, infertility, ectopic pregnancy and salpingitis. The microorganism is deficient in producing energy during life cycle and is required to attach to the host cell through elementary body (EB) to reach to the Golgi apparatus. The EB could be differentiated to the metabolically active non infectious replicative form, namely reticulate body (RB), which is able to inhibit cell apoptosis for long term survival. Mammalian heat shock proteins are evolutionary highly conserved molecular chaperones, which appear to have derived from procaryotic ancestors. Although HSP 60 is primarily considered a mitochondrial protein in mammals, 20 to $40 \%$ of cellular HSP 60 occurs in extra-mitochondrial sites. Amino acid sequences of human HSP 60 and C. trachomatis HSP 60 (serovar D) are 100\% similar. They are identified in four epitopes and 13 other peptides of various lengths with identity between $33 \%$ and $75 \%$, and these epitopes were present in all three domain of the molecule (Capello et al., 2009). Chlamydia trachomatis also secretes HSP $60 \mathrm{kDalton}$ possibly due to decreasing the external stress to the infection (Morrison, 1991). This molecule itself is capable of inducing strong inflammation in the fallopian tubes and antibody responses and similarly cell mediated immunity to HSP 60 is associated with tubal infertility and ectopic pregnancy. The interaction with human HSP 60, which has $48 \%$ homology with C. trachomatis HSP 60, may induce loss of pregnancy. Women with asymptomatic tubal infertility have an increased prevalence of antibodies against $C$. trachomatis and anti-HSP 60 (Sziller et al., 2008). Variety types of chlamydial HSP were identified with different properties to induce immunological response (Gérard et al., 2004). The implementation of public health measures to diagnose the recent developed infection in women at reproductive age and treatment is mandatory especially in the case of genital tract infection with the other microorganisms, which may induce the secretion of RB (Caldwell et al., 2003). The relevant data do not support the effectiveness of Chlamydial screening in general population younger than 25 years, however, high quality randomized trials are required to determine cost effectiveness or benefits (Low et al., 2009).

It has been suggested by some that exposure to C. trachomatis HSP 60 may be a risk factor for development of cancer (Di Felice et al., 2005), while the development of HSP 60 is also proposed to protect against malignancy (Capello et al., 2009). Chronic persistent infection with $C$. trachomatis to the upper genital tract is able to incur significant damage to the reproductive tract and proposed to induce ovarian cancer (Quirk \& Kupinski, 2001).

Various mechanisms are suggested for the effect of $C$. trachomatis inducing male infertility. Male reproductive system is separated from innate immunity, which may prevent 
immunization against one's own sperm. Infections are proposed to disrupt membranes and vascular barriers in testes, epididymis and prostate to initiate autoimmunization through introducing sperm with leucocytes or other inflammatory cells. C. trachomatis and $N$. gonorrheae are the most common pathogens for epididymitis and orchitis, which are common in the outpatient setting in men between 14 to 35 years of ages (Trojian et al., 2009). Although many cases of urethritis are idiopathic, C. trachomatis has been considered the most common infectious cause with many of these patients being symptomatic during the interview (Wetmore et al., 2009). On the other hand, though there are various studies investigating the relationship, influence of prostatitis induced by $C$. trachomatis on male infertility is uncertain (Cunningham \& Beagley, 2008). The surface membrane of sperm has various types of protein including HSP 65 and 70, which react with anti-sperm human IgG antibodies. Three of these proteins were also immunoprecipitated against $C$. trachomatis epitope of HSP 70, suggesting an association between genital tract infection, immunity to HSP 70 and reproductive failure (Naaby-Hansen \& Herr, 2010). The influence of leucocytospermia and DNA particles of sexually transmitted diseases (STD) on asymptomatic male infertility was investigated in a study conducted by Bezold et al. (Bezold et al., 2007). The incidence of STD was similar between patients with or without leucocytospermia. DNA particles from STD decreased sperm and motile sperm concentration, total sperm count, and neutral a-glucosidase concentration, whereas leucocytospermia was associated with a decrease in total sperm count, \% of normal forms, and fructose concentration. In addition to the decrease of spermatogenesis due to the destruction of reproductive system, male infertility seems to be influenced by both the infection itself and increased inflammation. In an in-vitro study, the persistence of $C$. trachomatis was demonstrated in the presence of ciprofloxacin and to a lesser extent of ofloxacin. These results reflect the clinical data that antibacterial susceptibility does not always guarantee the in-vivo success of the therapy (Dreses-Werringloer et al., 2000).

The association between prostate cancer and C. trachomatis infection was not determined, however increased seropositivity was found in men with benign prostate hyperplasia, suggesting inflammation-induced or facilitated enlargement (Hracek et al., 2011).

\subsection{Chlamydia and respiratory system}

Respiratory system is an important route of infection for Chlamydia pneumoniae. The microorganism is determined to be one of the infectious causes of sinusitis, otitis media, tonsillitis, laryngitis and chronic pharyngitis (Hsahiguchi et al., 1992, Hammaerschlag, 2000). Chronic infection in the upper respiratory tract was demonstrated to cause nasal polyps from the biopsy materials, possibly with increasing inflammation and epithelial cell destruction (Apan et al., 2007).

C. pneumonia is responsible for about $10-15 \%$ of community acquired pneumonias. C. trachomatis is also able to cause nasopharyngitis and pulmonary infection especially in the newborns. Infection may occur by direct transmission during the vaginal delivery and may be serologically positive in the earlier years of life. However, vertical transmission from the mother may result in the development of the neonatal conjunctivitis and pneumonia (Wu et al., 1999, Darville, 2005). Seropositivity to the C. pneumonia was found to be as high as $50 \%$ in young adults and 75\% for the elderly (Oba \& Salzman, 2007). 
A substantial body of evidence indicates the role of chronic infections in chronic pulmonary disease. The mechanism of chronic infection in disease process is not clear, but may involve a modification of the airway inflammatory response. Asthma is characterized by T-helper lymphocyte induced eosinophilic response that proceed to airway mucosal damage and increased responsiveness. There was no difference between the subjects who had atypical C. pneumonia and those who had nonatypical pneumonia in terms of asthma incidence, indicence being very high in both groups (Sutherland et al., 2004). Both of two serotypes of Chlamydiacea family were considered as infectious etiology for asthmatic patients in pediatric populations. Increased prevalence of viable $C$. pneumoniae was detected in samples from bronchoalveolar fluid in pediatric asthmatic patients, which constitutes about the half of the polymerase chain reaction (PCR) positive subjects with the microorganism (Webley et al., 2005). Chlamydia specific DNA strand was detected from bronchoalveolar fluid in about $67 \%$ of pediatric asthmatic patients. On the other hand, this observation is not able to explain $71 \%$ positive results obtained from PCR in non-asthmatic patients and increased incidence of asthma that was observed in certain subgroups (Webley et al., 2009).

C. pneumoniae is a causative organism in chronic severe form of asthma (Cook et al., 1998). Raised antibody titer to C. pneumoniae IgA was associated with increased neutrophil, monocyte count, and eosinophilic cationic protein in acute exacerbation of asthma (Wark et al., 2002). Elevated IgA antibody levels to C. pneumoniae were more commonly encountered in severe and moderate forms of asthma, suggesting chronic infection. However, antibody to C. pneumoniae HSP 60 was not considered as a useful marker of such an infection among the asthmatics (Hertzen et al., 2002).

Chronic obstructive pulmonary disease (COPD) is another chronic pulmonary pathology, which is leading cause of morbidity and mortality. There is a strong correlation between disease and smoking habit and about $10-20 \%$ of smokers developing COPD. Chronic C. pneumoniae infection as determined by persistent elevated IgA levels to the microorganism was associated with COPD and considered as an independent risk factor (Brandén et al., 2005). The relationship between severities of the disease and C. pneumoniae IgA antibody was demonstrated in another study, in which peak expiratory flow percentage of the predictive value was inversely correlated with the IgA antibody titers (Falck et al., 2002). On the other hand, the prevalence of IgG and IgM antibodies indicating acute infection was significantly increased in COPD patients when compared to the smoker control subjects, but no significant relation was found with IgA antibodies. Smoking was associated with increased level of C. pneumoniae serum antibody levels. It is presumed that smoking may facilitate C. pneumoniae infection in lung with chronic epithelial damage or promote deeper penetration into lung tissue to produce a greater antibody response (Karnak et al., 2001). High IgG and IgA antibody titers against C. pneumonia are linked with the severity of emphysema high resolution CT and increased IgA titers is also associated with decreased diffusion capacity to carbon monoxide (Kurashima et al., 2005).

Evidence indicates that there is a relation between chronic pulmonary infection with $C$. pneumonia and lung cancers. Antibody titer against to this organism is increased in cancer patients (Littman et al., 2004). The risk of cancer may increase about twofold in patients with 
elevated Ig A titers, specifically in squamous cell carcinomas and to a lesser extent in small cell and adenomatous cancers (Laurila et al., 1997). Increased seropositivity was found among smoker patients diagnosed with small cell cancer. This point rise concern about infection, which may be facilitated with chronic airway irritation with cigarette or chronic infection combined with increase in epithelial cell turnover that eventually leads to cancer (Samaras et al., 2010).

\subsection{Chlamydia and atherosclerosis}

Atherosclerosis is the main cause of death in the developed countries, inducing coronary heart disease, stroke or advancing organ failure. There are many contributing factor such as cigarette smoking, sedentary life style, increased weight due to hyper caloric, hyper cholesterolemic dietary habit, and low exercise. An association between atherosclerosis and infections has been suggested many times during the past century.

C. pneumonia, one of the infectious etiologies of atherosclerosis, was first demonstrated in the study conducted by Saikku et al. (Saikku et al, 1988). The microorganism first appears in the lower respiratory tract infected alveolar macrophages that transmigrate from the epithelium gain access to the circulation and reach atherosclerotic plaque. C. pneumonia may be capable of infecting a variety of cells including macrophages, vascular endothelial and smooth muscles. The lypopolisaccaride (LPS) component of the gram negative bacterial capsule is a potent inflammatory molecule, which changes the biology of the alveolar macrophages to attract low density lipoproteins and change their morphology (Mackman, 2000). The presence of organism on atherosclerotic plaque has been shown by various techniques, including PCR, immunohistochemistry, and electron microscopy (Leinonen \& Saikku, 2002, Campbell \& Kuo, 2004). The fact that organism is present in the atherosclerotic plaque but is rarely found in the healthy vasculature indicates that microorganism might spread through dissemination from primary infectious site with immune cells, namely $\mathrm{T}$ lymphocytes or monocytes (Liu et al., 2005). Also, it possibly requires weak regions between cell connections in endothelial layers for diapedes. Therefore, randomized antimicrobial programs were implemented to eradicate the infectious agent and failed success of long term therapies increased suspicion of atherogenesis theory. However, C. pneumonia is one of the possible causative organisms and all microorganisms can not be eradicated with a single antimicrobial agent. Recent cohort studies also indicated that antichlamydial therapy in Chlamydia positive patients led to no symptomatic improvement in peripheral vascular disease (Jaff et al., 2009). There is also no association between C. pneumonia bacteriophage or its antibody titers and acute coronary events (Patrick et al., 2005).

Beside the contributing factors, atherosclerosis may be initiated not only by direct invasion of microorganism itself but also by increasing and ongoing inflammation with such organisms. Inflammatory stimuli such as lipopolysaccarides of microorganisms may activate toll-like receptors (TLR) from immune response from macrophages and endothelial or smooth muscle cells. Once initiated, TLR are able to initiate inflammatory storm. Inborn deficiency including weaker response to the inflammatory stimuli may protect against cardiovascular diseases (Kiechl et al., 2002). Transient stimuli from certain microorganism had been found to be capable of inducing stimuli to TLR even when causative agent was 
undetected (Stassen et al., 2008). Leucocyte recruitment and accumulation to the atheroma initiates the second morphological event that accumulates lipid and changes to the foam cells. Smooth muscle cell migration and replication from underlying media to intima and cell death might complicate the atheroma. Volume increase under intima may lead to the rupture of underlying arterial vasa vasorum by restricting adequate oxygen or nutrient intake and hemorrhage may lead to further smooth muscle cell accumulation. The presence of C. pneumonia in the plaque may further augment the local inflammatory process. The other possible molecular mechanism induced by C. pneumonia is upregulation and expression of HSP 60, which induces cytokines including tumor necrosis factor- $\alpha$, interleukine-1 $\beta$ (IL1 $\beta$ ), IL 6, matrix metalloproteinases (MMP) from macrophages. In addition, C. pneumonia might increase $C$ reactive protein and contribute to instability or progression of the plaque (Miya et al., 2004). Specific microbial products such as LPS, HSP 60 or other virulence factors may provoke endothelial cell, producing remote infections. Also, the acute inflammation activates coagulation and fibrinolytic system, which changes balance in pro-coagulation site. Rupture of the plaque from its thinned fibrous cap and release of non-occlusive thrombi might produce clinically apparent occlusion in this activated coagulation state (Fazio et al., 2009). Infection with C. pneumonia is possibly involved with the pathogenesis of atherosclerosis early in life, such that antichlamydial antibiotic has no influence once inflammation and plaque has been established (Gattone et al., 2001). The organism may accelerate the progression of atherosclerosis by increasing and maintaining inflammation. It has been postulated in mice model that acceleration of atherosclerosis may be mediated through TLR and myeloid differentiation factor with liver $X$ receptor, which is important for cholesterol transportation (Naiki et al., 2008). In another animal model, an anti-oxidant, retinoic acid has been found to be effective against C. pneumonia-induced atherosclerosis by reducing foam cell formation in atherosclerotic lesions (Jiang et al., 2008). Recent evidence indicates that $C$. pneumonia may induce apoptosis and endothelial cell necrosis in the latter course of the infection, which is shown by the presence of chlamydial HSP 60 and with high mobility box protein 1, a strong pro-inflammatory molecule (Marino et al., 2008). However, inflammatory reaction seems to be host dependent and polyvalent in etiology. High antibody response is considered to be a more consistent marker for inflammation than seropositivity alone and high antibody response to multiple pathogens is a stronger marker of any single pathogen. Strong association was found between IL-6, CRP and fibrinogen levels with antibody levels (Nazmi et al., 2010). These findings may be partially explained the discrepancy between conflicting results arising on atherosclerosis, in studies which have methodological diversities.

\subsection{Chlamydia and neurologic disorders}

C. pneumonia may contribute to advancing atherosclerotic disease, which eventually leads to ischemic stroke. The presence of C. pneumonia was demonstrated in more than $70 \%$ of the severely stenotic specimens of carotic artery with immunohistochemical studies (Vink et al., 2001). The antibody titers including IgG and IgA against the organism were found to be higher especially in young stroke patients. Authors indicated that IgA class antibody titers were more important due to the limited half life and determined the persistence of chronic infection (Piechowski-Jóźwiak et al., 2007). There was an association between the risk of 
ischemic stroke and serum IgA titers, especially in large vessel atherosclerotic and lacunar stroke (Elkind et al., 2006). On the other hand, strong evidence on the relation between IgA titers and chronic infection is lacking because of inter-laboratory differences, limited half life and possible cross reactions with other types or microorganisms. Anti-C. pneumoniae antibodies were evaluated in HIV infected patients with coronary atherosclerosis. When atherosclerotic plaques from autopsy specimens were evaluated, there was limited data indicating the presence of $C$. pneumoniae in small cerebral vessels (Voorend et al., 2008). In a study conducted by Maggi et al, (Maggi et al, 2006) no significant difference was found between individuals in terms of IgA and IgG titers and no subject was positive for IgM, which led them to conclude that the damage of the carotid wall in patients infected with HIV-1 was not due to C. pneumonia. In contrast, C. pneumonia was found to be a risk factor for cardiovascular disease in HIV infected patients with low CD4 level and high HIV load (Tositti et al, 2005). The concurrence of hypercholesterolemia with C. pneumonia infection increased the risk of atherosclerosis by about three fold (Gaona-Flores et al, 2008). It has been also suggested that infected carotid plaques contribute to the systemic inflammatory markers in patients with stroke risk. The significant association of lipoprotein and phospholipase-A2 with of $C$. pneumoniae suggests an interaction between them in accelerating inflammation in atherosclerosis (Atik et al, 2010). There is limited data concerning genetic predisposition to the C. pneumoniae infection. Strong association was found between HLA B35 allele and serologic markers. Male sex and chronic smoking further increased the possibility of infection (Palikhe et al, 2008).

As an obligatory intracellular pathogen, C. pneumonia is able to reside in monocytes and macrophages of tissues and able to be reactivate according to the life cycle and host defense. It was proposed that, long term exposure to inflammatory cytokines and endothelial response may induce certain neurodegenerative disease including Alzheimer's disease, multiple sclerosis (MS), meningoencephalitis and neurobehavioral disorders (Yucesan \& Sriram, 2001, Stratton \& Sriram, 2003).

Alzheimer's disease (AD) causes dementia with advancing age with the atrophy or death of the certain regions of brain. Two clinical form of disease has been classified as genetically determined: namely, early onset and late onset non-familial and progressive neurodegenerative form, which is the most common and severe form of dementia. The association between $\mathrm{AD}$ with C. pneumoniae infection was first demonstrated by Balin et al, and $90 \%$ positivity was shown in brain specimens using PCR technique. Electron microscopic and immunohisto-chemistry studies also indicated that EB and RB like particles were found in the brains of affected individuals, while no labeling was detected in controls (Balin et al.,1998). These results were further confirmed in a study subjecting brain specimens of $\mathrm{AD}$ and controls during autopsy in which increased prevalence of $C$. pneumonia RNA was observed with AD (Gérard HC et al, 2006). Furthermore, strong association was determined between apolipoprotein E $\varepsilon 4$ genotype and C. pneumoniae (Gérard HC et al., 1999). The olfactory epithelium has been proposed as the primary infectious site and the pathogen seems to reach to the olfactory bulb and olfactory cortex and then neuronal damage may progress (Balin \& Appelt, 2001). Long term antibiotic therapy, including doxycycline and rifampin, slowed the course of cognitive impairment (Loeb et al., 2004). Metal protein attenuating compounds have been shown to decrease beta amyloid plaques in animal models and antiprotozoal metal chelator clioquinol was used for treatment (Finefrock et al., 2003, Cahoon, 2009). C. pneumoniae is also associated 
with AIDS-demantia complex, a HIV-induced inflammatory parenchymal disorder of the brain. The presence of microorganism was confirmed at a high rate in using PCR. These findings should be cautiously interpreted as whether the source of infection is reactivation due to immune suppression or superimposed recent infection remains to be clarified (Contini et al., 2003).

Multiple sclerosis (MS), an autoimmune chronic demyelinating disorder of the CNS with unknown etiology appears with episodes of remission and relapse, or is present in progressive forms. Disease has high economic burden and disability potential and affects about 1-2 person in 1000. Perivascular inflammation, gliosis and demyelinating plaque formations are considered as classical the pathologic features (Barnett \& Sutton, 2006). Perivascular cell infiltration was presumed to initiate the involvement of glial cells in the earlier and astrocytes in the later phase of the disease. Various types of microorganisms including Chlamydia are assumed to induce inflammation through TLR 3 and 4 dependent mechanisms (Joyee \& Yang, 2008). Genetic predisposition with a combination of infectious agents has been implicated in MS pathogenesis. The presence of $C$. pneumoniae is still under debate and shows a great variability from 0 to $43 \%$ in different studies using PCR techniques (Contini et al., 2010). Several authors indicate that the presence of microorganism may partially influence the occurrence of MS, being linked to the progressive form of the disease (Munger et al, 2003). When compared to the controls, the increased frequency of detection of HSP 60 and 16S rRNA in the CSF samples from MS patients indicates the metabolic activity of the microorganism (Dong-Si et al., 2004). Intrathecal synthesis of antichlamydial IgG, indicating the infectious cause, was more frequent in MS patients than in non-infectious neural diseases (Fainardi et al., 2004). The increased presence of C. pneumonia was demonstrated in a study investigating autopsy samples of MS patients, which looked for anti-chlamydial monoclonal antibodies using immunohistochemical staining in brain slices. The electron microscopy also detected chlamydial EB in four of ten MS patients but none in the controls (Sriram et al., 2005). A large meta-analysis including 26 studies was not able to conclude that $C$. pneumoniae as a causal relationship with MS (Bagos et al., 2006). Anti microbial therapy in patients with MS requires validated multi-central studies, involving all infectious cycles of the microorganism (Stratton \& Wheldon, 2007). The current information indicates that, the causal relationship between C. pneumoniae with MS is still controversial. Infection may be activated or supervene in the course of the disease.

There is a paucity of reports regarding the relation of $C$. pneumoniae with meningoencephalitis. These patients are young, have neurological symptoms or radiographic evidence and also have acute symptoms of respiratory infection, and laboratory evidence indicating C. pneumoniae. Acute demyelinating encephalitis, cerebellar axatia and Gullian Barre are some of the clinical forms in which faster recovery after antibiotic therapy demonstrates the relation between microorganism and neurological presentations (Contini et al., 2010).

Reports indicating relationship between C. pneumoniae and affective and neurobehavioral diseases are also sparse. Autism spectrum disorders (ASD), constitute a group of behavioral diseases such as autism, attention deficit disorder, Asperger's syndrome with unknown etiology. Genetic predisposition, environmental factors, educational and socioeconomic status of the family was determined as possible reasons (Nicholson \& 
Sztmari, 2003). Infection may be a cofactor in progression of the disease and C. pneumoniae is considered as a causative organism along with Mycoplasma species or infections from herpes virus (Chia \& L.Y. Chia, 1999). Chlamydiacea family has been postulated to cause of schizophrenia owing to persistence of high IgA levels in subjects. Fellerhoff et al. found a significant prevalence of C. psittaci, C. pneumoniae, and C. trachomatis (50\%) compared to the controls $(\sim 7 \%)$. While antipsycotic drugs were inefficient, treatment including in-vitro activated immune cells and antibiotics showed improvement of the mental illness (Fellerhoff et al., 2005).

\subsection{Chlamydiaceae and systemic disorders}

Reactive arthritis is currently accepted to be associated with Chlamydial infections or other enteric or sexually acquired infections.

C. trachomatis and to a lesser extent C. pneumonia is determined to be one of the most common infectious etiological agents in reactive arthritis (Carter, 2006, Braun et al, 1994). Specifically, Chlamydial source of reactive arthritis was estimated about to be $\sim 5 \%$ and $78 \%$ of these infections were dormant and asymptomatic during initial infection (Rich et al., 1996). In comparison with osteoarthritis, Chlamydia species have been demonstrated to be associated with undifferentiated spondylarthritis (a subgroup of reactive arthritis) using PCR at a higher rate in synovial tissue, than blood serological values. The genetic background influencing predisposition or host defense of Chlamydia-induced arthritis remains to be elucidated and HLA-B27 positivity was found to be lower than the other source of reactive arthritis and appeared to be less progressive in HLA-B27 negative patients (Carter et al., 2009). Increased frequency of C. trachomatis infection was also detected in patients with ankylosing spondilitis as determined with serologic analysis including immunoblotting (Csango et al., 1987). In addition, psoriatic arthritis (PsA) seems to be a candidate for investigations on the etiologic role of chlamydial infections. In their study Silveira et al (Silveira et al., 1993) indicated the prevalence of C. trachomatis infection in patients with $\mathrm{SpA}$, which demonstrated a significant frequency of positive urogenital $C$. trachomatis culture (22\%) as well as elevated levels of IgG antibodies (36\%) or IgM antibodies $(14 \%)$ against $C$. trachomatis in patients with PsA. On the contrary, there was only association of rheumatoid arthritis with $C$. trachomatis in a study investigating the possible infectious etiology in patients with different group of seronegative spondyloarthropathies (Lapadula et al., 1988).

The infectious etiology in diabetes has not been confirmed due to its relatively lower incidence compared with the seropositivity of the possible community acquired microorganisms (Lutsey et al., 2009). Yet, several studies indicate that infection with $C$. pneumoniae might influence the time related outcome of diabetes in a subgroup of patients, thought to be a possible genetic predisposition. C. pneumoniae with chronic low grade inflammation induces insulin resistance in healthy middle aged man and correlation increased with body mass index and seropositivity to the multiple microorganisms (Fernández-Real et al., 2006). These results were further confirmed with an animal model demonstrating that $C$. pneumoniae induces long lasting insulin resistance and inflammation in obese mice. Anti TNF-a or antibiotic treatment prevents insulin resistance (Wang et al., 2009). Increased seropositivity to C. pneumoniae IgA and IgG in diabetes was associated with 
the secondary cardiovascular events including myocardial infarction, stroke, or cardiovascular death, having possible relation with chlamydial HSP 60. The relation or role of human HSP 60 in disease progress and complications remains to be determined with large scale prospective studies (Guech-Ongey et al., 2009).

Behçet's disease (BD) is an inflammatory disorder of unknown etiology characterized by recurrent oral aphtous ulcers, genital ulcers, uveitis and skin lesions. Patients with BD demonstrated increased IgA and IgG titers to C. pneumoniae when compared with controls (Ayaşlığlu et al., 2004). Intestinal lesions of BD expressing interferon- $\gamma$, tumor necrosis factor-a, interleukin 12 mRNA and HSP 60 indicates possible involvement of microbial HSP 60 in the pathogenesis of intestinal $\mathrm{BD}$, but the relation with Chlamydiae remains to be determined (Imamura et al., 2005).

\section{Conclusion}

The serotypes of Chlamydiaceae tend to cause chronic infection and are involved in various types of disorders. Lacks of standardized methods for diagnosis or laboratory tests that partially reflect the activity of the microorganism is the main problem. Further insight on the life cycle of these ubiquitous bacteria's is mandatory, especially on HSP 60 and interactions with host, to elucidate the therapeutic options better. Genetic predisposition is another issue that needs to be illuminated to determine the individuals who are prone or resistant to disease activity.

\section{References}

Apan, T.Z., Alpay, D., \& Alpay, Y. (2007) The possible association of Chlamydia pneumoniae infection with nasal polyps. European archives of oto-rhino-laryngology, V.264, No.1, pp.27-31, ISSN: 0937-4477.

Atik, B., Johnstone, C., \& Dean D. (2010) Association of carotid plaque Lp-PLA2 with macrophages and Chlamydia pneumoniae infection among patients at risk for stroke. PLoS ONE V.5, No.6, e11026, ISSN: 1932-6203.

Ayaşlıŏ̆lu, E., Düzgün, N., Erkek, E, \& Inal, A. (2004) Evidence of chronic Chlamydia pneumoniae infection in patients with Behçet's disease. Scandinavian Journal of Infectious Disase, V.36, N.6-7, pp.428-30, ISSN: 0036-5548.

Bagos, P.G., Nikolopoulos, G., \& Ioannidis, A. (2006) Chlamydia pneumoniae infection and the risk of multipl sclerosis: a meta analysis. Multipl Sclerosis, Vol.12, N.4, pp.397-411, ISSN: 1352-4585.

Balin, B.J., Gérard, H.C., Arking, E.J., Appelt, D.M., Branigan, P.J., Abrams, J.T., WhittumHudson, J.A. \& Hudson, A.P. (1998) Identification and localization of Chlamydia pneumoniae in the Alzheimer's brain. Medical Microbiololgy and Immunology V.187, N.1, pp.23-42, ISSN: 0300-8584.

Balin, B.J. \& Appelt D.M. (2001) Role of infection in Alzheimer's disease. The Journal of the American Osteopathic Association Vol.101, N.12 suppl Pt1, pp.S1-S6, ISSN: 0098-6151.

Barnett, M.H. \& Sutton, I. (2006) The pathology of multiple clerosis: a paradigm shift. Current Opinion in Neurology Vol.19, N.3, pp.242-247, ISSN: 1350-7540. 
Bezold, G., Politch, J.A., Kiviat, N.B., Kuypers, J.M., Wolff, H., \& Anderson, D.J. (2007) Prevalence of sexually transmissible pathogens in semen from asymptomatic male infertility patients with and without leucocytospermia. Fertility and Sterility Vol.87, N.5, pp.1087-1097, ISSN: 0015-0282.

Brandén, E., Koyi, H., Gnarpe, J., \& Gnarpe, H. (2005) Chronic Chlamydia pneumoniae infection is a risk factor for the development of COPD. Respiratoy Medicine V.99, N.1, pp.20-26, ISSN: 0954-6111.

Braun, J., Laitko, S., Treharne, J., Eggens, U., Wu, P., Distler, A., \& Sieper, J. (1994) Chlamyida pneumoniae--a new causative agent of reactive arthritis and undifferentiated oligoarthritis. Annals of Rheumatologic Disease V.53, N.2, pp.100105, ISSN: 0003-4967.

Burton, M.J. (2007) Trachoma: an overview. British Medical Bullettin V.84, pp.99-116, ISSN: 0007-1420.

Burton, M.J., Bowman, R.J.C., Faal, H., Aryee, E.A.N., Ikumapayi, U.N., Alexander, N.D.E., Adegbola, R.A., West, S.K., Mabey, D.C.W., Foster, A., Johnson, G.J., \& Bailey, R.L. (2005a) Long term outcome of trichiasis surgery in the Gambia. The British Journal of Ophtalmology V.89, N.5, pp.575-579, ISSN: 0007-1161.

Burton, M.J., Kinteh, F., Jallow, O., Sillah, A., Ikumapayi, U.N., Alexander, N.D.E., Adegbola, R.A., Faal, H., Mabey, D.C.W., Foster, A., Johnson; G.J., \& Bailey, R.L. (2005b) A randomized controlled trial of azithromycin following surgery for trachomatous trichiasis in the Gambia. The British Journal of Ophtalmology Vol.89, N.10, pp.1282-1288, ISSN: 0007-1161.

Cahoon, L. (2009) The curious case of clioquinol. Nature medicine V.15, N.5, pp.354-359, ISSN: 1078-8956.

Caldwell, H.D., Wood, H., Crane, D., Bailey, R., Jones, R.B., Mabey, D.;, Maclean, I., Mohammed, Z., Peeling, R., Roshick, C., Schachter, J., Solomon, A.W., Stamm, W.E., Suchland, R.J., Taylor, L., West, S.K., Quinn, T.C., Belland, R.J., \& McClarty, G. (2003) Polymorphism in Chlamydia trachomatis tryptophan synthase genes differntiate between genital and ocular isolates. The Journal of clinical investigation Vol.111, N. 11, pp.1757-1769, ISSN: 0021-9738.

Campbell, L.A., \& Kuo, C.C. (2004) Chlamydia pneumoniae-an infectious risk factor for atherosclerosis? Nature reviews. Microbiology Vol.2, N.1, pp.23-32, ISSN: 1740-1526.

Capello, F., de Macario, E.C., Di Felice, V., Zummo, G., \& Macario, A.J.L. (2009) Chlamydia trachomatis infection and anti-hsp60 immunity: the two sides of the coin. PLoS pathogens Vol.5, N.8, e1000552, ISSN: 1553-7366.

Carter, J.D. (2006) Reactive arthritis: defined etiologies, emerging pathophysiology, unresolved treatment. Infectious Disease Clininics of Noth America Vol.20, N.4, pp.827-847, ISSN: 0891-5520.

Carter, C.D., Gérard, H.C., Espinoza, L.R., Ricca, L.R., Valeriano, J., Snelgrove, J., Oszust, C., Vasey, F.B., \& Hodson, A.P. (2009) Chlamyidae as etiologic agents in chronic undifferentiated spndylartritis. Arthritis and rheumatism V.60, N.5, pp.1311-1316, ISSN: 0004-3591.

Chanudet, E., Zhou, Y., Bacon, C.M., Wotherspoon, A.C., Müller-Hermelink, H.K., Adam, P., Dong, H.Y., de Jong, D., Li, Y., Wei, R., Gong, X., Wu, Q., Ranaldi, R., Goteri, G., 
Pileri, S.A., Ye, H., Hamoudi, R.A., Liu, H., Radford, J., \& Du, M.Q. (2006) Chlamydia psittaci is variably associated with ocular adnexal MALT lymphoma in different geographical regions. The Journal of Pathology. V.209, N.3, pp.344-51, ISSN: 0022-3417.

Chia, J.K.S., \& Chia, L.Y. (1999) Chronic Chlamydia pneumoniae infection: atreatable cause of chronic fatigue syndrome. Clinical Infectious Disease V.29, N.2, pp.452-453, ISSN: 1058-4838.

Contini, C., Fainardi, E., Seraceni, S., Granieri, E., Castellazzi, M., \& Cultrera, R. (2003) Molecular identification and antibody testing of Chlamydophila pneumoniae in a subgroup of patients with HIV-associated dementia complex, preliminary results. Journal of neuroimmunology, V.136, N.1-2, pp.172-177, ISSN: 0165-5728.

Contini, C., Seraceni, S., Cultrera, R., Castellazzi, M., Granieri, M., \& Finardi, E. (2010) Chlamydophyla pneumonia: infection and its role in neurological disorders. Interdisciplinay Perspectives in Infectious Disease 2010273573 Epub 2010 Feb 21, ISSN: 1687-708X.

Cook, P.J., Davies, P., Tunnicliffe, W., Ayres, J.G., Honeybourne, D., \& Wise, R. (1998) Chlamydia pneumoniae and asthma. Thorax V.53, N.4, pp.254-259, ISSN: 0040-6376.

Csango, P.A., Upsahl, M.T., Romberg, O., Kornstad, L., \& Sarov, I. (1987) Chlamydia trachomatis serology in ankylosing spondylitis. Clinical Rheumatology, V.6, N.3, pp.384-90, ISSN: 0770-3198.

Cunningham, K.A. \& Beagley, K.W. (2008) Male genital tract Chlamydial infection: implications for pathology and infertility. Biology of reproduction, V.79, N.2, pp.180189, ISSN: 0006-3363.

Darville, T. (2005) Chlamyida trachomatis infections in neonates and young children. Seminars in pediatric infectious diseases, V.16 N.4, pp.235-44, ISSN: 1045-1870.

Di Felice, V., David, S., Cappello, F., Farina, F., \& Zummo, G. (2005) Is chlamydial heat shock protein 60 a risk factor for oncogenesis? Cellular and molecular life sciences V.62, N.1, pp.4-9, ISSN: 1420-682X.

Dong-Si, T., Weber, J., Liu, Y.B., Buhmann, C., Bauer, H., Bendl, C., Schnitzler, P., GrondGinsbach, C., \& Grau, A.J. (2004) Increased prevalence of gene transcription by Chlamydia pneumoniae in cerebrospinal fluid of patients with relapsing-remitting multiple sclerosis. Journal of neurology, V.251, N.5, pp.542-547, ISSN: 0340-5354.

Dreses-Werringloer, V., Padubrin, I., Jürgens-Saathoff, B., Hudson, A.P., Zeidler, H., \& Köhler, L. (2000) Persistence of is induced by ciprofloxacin and ofloxacin in vitro. Antimicrobial agents and chemotherapy, V.44, N.12, pp.3288-3297, ISSN: 0066-4804.

Elkind, M.S.V., Tondella, M.L.C., Feikin, D.R., Fields, B.S., Homma, S., \& Di Tullio, M.R. (2006) Seropositivity to Chlamydia pneumoniae is associated with risk of first ischemic stroke. Stroke, V.37, N.3, pp.790-795, ISSN: 0039-2499.

Fainardi, E., Castellazzi, M., Casetta, I., Cultrera, R., Vaghi L, Granieri E, \& Contini C. (2004) Intrathecal production of Chlamydia pneumoniae -specific high-affinity antibodies is signidficantly associated to a subset of multipl sclerosis patients with progressive forms. Journal of the neurological sciences, V.217, N.2, pp.181-188, ISSN: 0022-510X. 
Falck, G., Gnarpe, J., Hansson, L.O., Svärdsudd, K., \& Gnarpe, H. (2002) Comparison of individuals with and without specific IgA antibodies to Chlamydia pneumoniae. Chest, V.122, N.5, pp.1587-1593, ISSN: 0012-3692.

Fazio, G., Giovino, M., Gullotti, A., Bacarella, D., Novo, G., \& Novo, S. (2009) Atherosclerosis, inflammation and Chlamydia pneumoniae. World journal of cardiology, V.1, N.1, pp.31-40, ISSN: 1949-8462.

Fellerhoff, B., Laumbacher, B., \& Wank, R. (2005) High risk of schizophrenia and other mental disorders associated with clamydial infections: hypothesis to combine drug treatment and adoptive immunotherapy. Medical hypotheses, V.65, N.2, pp.243-252, ISSN: 0306-9877.

Fernández-Real, J.M., Ferri, M.J., López-Bermejo, A., Recasens, M., Vendrell, J., \& Ricart, W. (2006) Burden of infection and insulin resistance in healthy middle-aged man. Diabetes Care, V.29, N.5, pp.1058-1064, ISSN: 0149-5992.

Ferreri, A.J., Guidoboni, M., Ponzoni, M., De Conciliis, C., Dell'Oro, S., Fleischhauer, K., Caggiari, L., Lettini, A.A., Dal Cin, E., Ieri, R., Freschi, M., Villa, E., Boiocchi, M., \& Dolcetti, R. (2004) Evidence for an association between Chlamydia psittaci and ocular adnexal lymphomas. Journal of the National Cancer Institute, V.96, N.8, pp.58694, ISSN: 0027-8874.

Finefrock, A.E., Bush, A.I., \& Doraiswamy, P.M. (2003) Current status of metals as therapeutic targets in Alzheimer's disease. Journal of the American Geriatrics Society, V.51, N.8, pp.1143-1148, ISSN: 0002-8614.

Fujimoto, T., Somoda, K.H., Hijioka, K., Sato, K., Takeda, A., Hasegawa, E., Oshima, Y., \& Ishibashi, T. (2010) Choroidal neovascularization enhanced by Chlamydia pneumoniae via Toll-like receptor2 in the retinal pigment epithelium. Investigative ophthalmology \& visual science, V.51, N.9, pp.4694-702, ISSN: 0146-0404.

Gaona-Flores, V., García-Elorriaga, G., Valerio-Minero, M., González-Veyrand, E., Navarrete-Castro, R., Palacios-Jiménez, N., Del Rey-Pineda, G., González-Bonilla, C., \& Monasta, L. (2008) Anti-Chlamydophila pneumoniae antibodies as associated factor for carotid atherosclerosis in patients with AIDS. Current HIV research, V.6, N.3, pp.267-271, ISSN: 1570-162X.

Gattone, M., Iacoveillo, L., Colombo, M., Castelnuovo, A.D., Soffiantino, F., Gramoni, A., Picco, D., Benedetta, M., \& Giannuzzi, P. (2001) Chlamydia pneumonia and cytomegalovirus seropositivity, inflammatory markers, and the risk of myocardial infarction at a yound age. American heart journal, V.142, N.4, pp.633-640, ISSN: 0002-8703.

Gérard, H.C., Whittum-Hudson, J.A., Schumacher, H.R., \& Hudson, A.P. (2004) Differentail expression of three Chlamydia trachomatis hsp-60 encoding genes in active vs. persistent infections. Microbial pathogenesis, V.36, N.1, pp.35-39, ISSN: 0882-4010.

Gérard, H.C., Dreses-Werringloer, U., Wildt, K.S., Deka, S., Oszust, C., Balin, B.J., Frey, W.H. 2nd, Bordayo, E.Z., Whittum-Hudson, J.A., \& Hudson, A.P. (2006) Chlamydophila (Chlamydia) pneumonia in Alzheimer's brain. FEMS immunology and medical microbiology, V.48, N.3, pp.355-366, ISSN: 0928-8244. 
Gérard, H.C., Wang, G.F., Balin, B.J., Schumacher, H.R., Hudson, A.P. (1999) Frequency of apolipoprotein E (APOE) allele types in patients with Chlamydia-associated arthritis and other arthritides. Microbial pathogenesis, V.26, N.1, pp.35-43, ISSN: 0882-4010.

Guech-Ongey, M., Brenner, H., Twardella, D., \& Rothenbacher, D. (2006) Chlamydia pneumoniae heat shock proteins 60 and risk of secondary cardiovascular events in patients with coronary heart disease under special consideration of diabetes: a prospective study. BMC cardiovascular disorders, V.6, pp.17, http//www.biomedcentral.com/1471-2261/6/17. ISSN: 1471-2261.

Hammaerschlag, M.R. (2000) The role of Chlamydia in upper respiratory tract infections. Current infectious disease reports, V.2, N.2, pp.115-120, ISSN: 1523-3847.

Hertzen, L.V., Vasankari, T., Lippo, K., Wahlstöm, E., \& Puolakkainen, M. (2002) Chlamydia pneumoniae and severity of asthma. Scandinavian journal of infectious diseases, V.34, N.1, pp.22-27. ISSN: 0036-5548.

Holland, M.J., Faal, N., Sarr, I., Joof, H., Laye, M., Cameron, E., Pemberton-Pigot, F., Dockrell, H.M., Bailey, R.L., \& Mabey, D.C.W. (2006) The frequency of Chlamydia trachomatis major outer membrane protein-specific CD8+ T lymphocytes in active trachoma is associated with current ocular infection. Infection and immunity, V.74, N.3, pp.1565-1572, ISSN: 0019-9567.

Hong, K.C., Schachter, J., Moncada, J., Zhou, Z., House, J., \& Lietman, T.M. (2009) Lack of macrolide resistance in Chlamydia trachomatis after mass azithromycin distributions for trachoma. Emerging infectious diseases, V.15, N.7, pp.1088-1090, ISSN: 1080-6040.

Hracek, J., Urban, M., Hamsikova, E., Tachezy, R., Eis, V., Brabec, M., \& Heracek, J. (2011) Serum antibodies against genitourinary infectious agents in prostate cancer and benign prostate hyperplasia patients: a case-control study. BMC Cancer, V.11: pp.53, ISSN: 1471-2407.

Hsahiguchi, K., Ogawa, H., \& Kazuyama, Y. (1992) Seroprevalence of Chlamydia pneumoniae infections in otolarygologic diseases. The Journal of laryngology and otology, V.106, N.3, pp.208-210, ISSN: 0022-2151.

Imamura, Y., Kurokawa, M.S., Yoshikiwa, H., Nara, K., Takada, E., Masuda, C., Tsukikawa, S., Ozaki, S., Matsuda, T., \& Suzuki, N. (2005) Involvement of Th1 cells and heat shock protein in the patogenesis of intestinal Behçet's disease. Clinical and experimental immunology, V.139, N.2, pp.371-378, ISSN: 0009-9104.

Jaff, M.R., Dale, R.A., Creager, M.A., Lipicky, R.J., Constant, J., Campbell, L.A., \& Hiatt, W.R. (2009) Anti-Chlamydial antibiotic therapy for symptom improvement in peripheral artery disease. Circulation, V.119, N3, pp.452-458, ISSN: 0009-7322.

Jiang, S.J., Campbell, L.A., Berry, M.W., Rosenfeld, M.E., \& Kou, C.C. (2008) Retinoic acid prevents Chlamydia pneumoniae induced foam cell development in a mouse model of atherosclerosis. Microbes and infection, V.10, N.12-13, pp.1393-1397, ISSN: 12864579 .

Joyee, A.G., \& Yang, X. (2008) Role of toll-like receptors in immune responses to chlamydial infections. Current pharmaceutical design, V.14, N.6, pp.593-600, ISSN: 1381-6128. 
Karnak, D., Bengisun, S., Beder, S., \& Kayacan, O. (2001) Chlamydia pneumoniae infection and acute exacerbation of chronic obstructive pulmonary disease (COPD). Respiratory medicine, V.95, N.10, pp.811-816, ISSN: 0954-6111.

Kiechl, S., Lorenz, E., Reindl, M., Wiedermann, C.J., Oberhollenzer, F., Bonora, E., Willeit, J., \& Schwartz, D.A. (2002) Toll-like 4 polymorphism and atherogenesis. The New England journal of medicine, V.347, N.3, pp.185-192, ISSN: 0028-4793.

Kurashima, K., Kanuchi, T., Takayanagi, N., Sato, N., Tokunaga, D., Ubukata, M., Yanagisawa, T., Sugita, Y., \& Kanazawa, M. (2005) Serum IgG and IgA antibodies to Chlamydia pneumoniae and severity of emphysema. Respirology, V.10, N.5, pp.572578, ISSN: 1323-7799.

Lapadula, G., Covelli, M., \& Numo, R. (1988) Antibacterial pattern in seronegative spondyloarthropathies. Clinical and experimental rheumatology, V.6, N.4, pp.385-390, ISSN: 0392-856X.

Laurila, A.L., Anttila, T., Läärä, E., Bloigu, A., Virtamo, J., Albanes, D., Leinonen, M., \& Saikku, P. (1997) Serological evidence of an association between Chlamydia pneumoniae infection and lung cancer. International journal of cancer, V.74, N.1, pp.31-34, ISSN: 0020-7136.

Leinonen, M., \& Saikku, P. (2002) Evidence for infectious agents in cardiovascular disease and atherosclerosis. The Lancet infectious diseases, V.2, N.1, pp.11-17, ISSN: 14733099.

Littman, A.J., Thornquist, M.D., White, E., Jackson, L.A., Goodman, G.E., \& Vaughan, T.L. (2004) Prior lung disease and risk of lung cancer in a large prospective study. Cancer causes $\mathcal{E}$ control, V.15, N.8, pp.819-827, ISSN: 0957-5243.

Liu, R., Yamamoto, M., Moroi, M., Kubota, T., Ono, T., Funatsu, A., Komatsu, H., Tsuji, T., Hara, H., Nakamura, M., Hirai, H., \& Yamaguchi, T. (2005) Chlamydia pneumonia immunoreactivity in coronary artery plaques of patients with acute coronary syndromes and its relation with serology. American heart journal, V.150, N.4, pp.681688, ISSN: 0002-8703.

Loeb, M.B., Molloy, D.W., Smieja, M., Standish, T., Goldsmith, C.H., Mahony, J., Smith, S., Borrie, M., Decoteau, E., Davidson, W., McDougall, A., Gnarpe, J., O'Donnell, M., \& Chernesky, M. (2004) A randomized, controlled trial of doxycycline and rifampin for patients with Alzheimer's disease. Journal of the American Geriatrics Society, V.52, N.3, pp.381-387, ISSN: 0002-8614.

Low, N., Bender, N., Nartey, L., Shang, A., \& Stephenson, J.M. (2009) Effectiveness of Chlamydia screening: systematic review. International journal of epidemiology, V.38, N.2, pp.435-448, ISSN: 0300-5771.

Lutsey, P.L., Pankow, J.S., Beroni, A.G., Szklo, M., \& Folsom, A.R. (2009) Serologic evidence of infections and type 2 diabetes: the multiethnic study of antehrosclerosis. Diabetic medicine, V.26, N.2, pp.149-152, ISSN: 0742-3071.

Mabey, D., \& Peeling, R.W. (2002) Lymphogranuloma venereum. Sexually transmitted infections, V.78, N.2, pp.90-92, ISSN: 1368-4973.

Mackman, N. (2000) Lipopolysaccaride induction of gene expression in human monocytic cells. Immunologic research, V.21, N.2-3, pp:247-251, ISSN: 0257-277X. 
Maggi, P., Monno, R., Chirianni, A., Gargiulo, M., Carito, V., Fumarola, L., Perilli, F., Lillo, A., Bellacosa, C., Panebianco, A., Epifani, G., \& Regina G. (2006) Role of Chlamydia infection in the pathogenesis of atherosclerotic plaques in HIV-1 positive patients. In Vivo, V.20, N.3, pp.409-414, ISSN: 0258-851X.

Marino, J., Stoeckli, I., Walch, M., Latinovic-Golic, S., Sundstroem, H., Groscurth, P., Ziegler, U., \& Dumrese, C. (2008) Chlamydophila pneumoniae derived from inclusions late in the infectious cycle induce aponecrosis in human aortic endothelial cells. BMC microbiology, V.8: pp.32, ISSN: 1471-2180.

Melese, M., West, E.S., Alemayehu, W., Munoz, B., Worku, A., Gaydos, C.A., \& West, S.K. (2005) Characteristics of trichiasis patients presenting for surgery in rural Ethiopia. The British journal of ophthalmology, V.89, N.9, pp.1084-1088, ISSN: 0007-1161.

Miya, N., Oguchi, S., Watanabe, I., \& Kanmatsuse, K. (2004) Relation of secretory phospholipase $\mathrm{A}(2)$ and high sensitivity C-reactive protein to Chlamydia pneumonia infection in acute coronary syndromes. Circulation journal, V.68, N.7, pp.628-633, ISSN: 1346-9843.

Morrison, R.P., Belland, R.J., Lyng, K., \& Caldwell, H.D. (1989) Chlamydial disease pathogenesis: the $57-\mathrm{kD}$ chlamydial hypersensitivity antigen is a stress response protein. The Journal of experimental medicine, V.170, N.4, pp.1271-1283, ISSN: 00221007.

Morrison, R.P. (1991) Chlamydial hsp60 and immunopathogenesis of chlamydial disease. Seminars in immunology, V.3, N.1, pp.25-33, ISSN: 1044-5323.

Munger, K.L., Peeling, W., Hernán, A., Chasan-Taber, L., Olek, M.J., Hankinson, S.E., Hunter, D., \& Ascherio, A. (2003) Infection with Chlamydia pneumoniae and risk of multipl sclerosis. Epidemiology, V.14, N.2 pp.141-147, ISSN: 1044-3983.

Naaby-Hansen, S., Herr, J.C. (2010) Heat shock proteins on the human sperm surface. Journal of reproductive immunology, V.84, N,1, pp.32-40, ISSN: 0165-0378.

Naiki, Y., Sorrentino, R., Wong, M.H., Michelsen, K.S., Schimada, K., Chen, S., Yilmaz, A., Slepenkin, A., Schröder, N.W.J., Crother, T.R., Bulut, Y., Doherty, T.M., Bradley, M., Shaposhnik Z., Peterson, E.M., Tontonoz, P., Shah, P.K., \& Arditi, M. (2008) TLR/MyD88 and LXRa signaling pathways eciprocally control Chlamydia pneumoniae-induced acceleration of atherosclerosis. The Journal of immunology, V.181, N.10, pp.7176-7185, ISSN: 0022-1767.

Nazmi, A., Diez Roux, A.V., Jenny, N.S., Tsai, M.Y., Szklo, M., \& Aiello, A.E. (2010) The influence of persistent pathogens on circulating levels of inflammatory markers: a cross-sectional analysis from the multi-ethnic study of atherosclerosis. BMC Public Health, V.10, pp.706, ISSN: 1471-2458.

Nicholson, R., \& Sztmari, P. (2003) Genetic and neurodevelopmental influences in autistic disorder. Canadian journal of psychiatry, V.48, N.8, pp.526-537, ISSN: 0706-7437.

Oba, Y., \& Salzman G. (2007) Chlamydial pneumonias: overview of infection with the three main chlamydial species that cause respiratory disease in humans. eMedicine, http://www.emedicine.com/med/TOPIC341.HTM.

Palikhe, A., Lokki, M.L., Saikku, P., Leinonen, M., Paldanius, M., Seppänen, M., Valtonen, V., Nieminen, M.S., \& Sinisalo, J. (2008) Association of Chlamydia pneumoniae 
infection with HLA-B35 in patients with coronary artery disease. Clinical and vaccine immunology, V.15, N.1, pp.55-59, ISSN: 1556-6811.

Patrick, D.M., Karunakaran, K., Levy, A.R., Gin, K., Remple, V., Chong, M., Abbey, H., Tarry, L., Shen, C., \& Brunham, R.C. (2005) Chlamydia bacteriophage: no role in acute coronary events? The Canadian journal of infectious diseases $\mathcal{E}$ medical microbiology, V.16, N.5, pp.298-300, ISSN: 1712-9532.

Piechowski-Jóźwiak, B., Mickielewicz, A., Gaciong, Z., Berent, H., \& Kwieciński, H. (2007) Elevated levels of anti-Chlamydia pneumoniae Ig A and IgG antibodies of young adults with ischemic stroke. Acta neurologica Scandinavica, V.116 N.3, pp.144-149, ISSN: 0001-6314.

Quirk, J.T., \& Kupinski, J.M. (2001) Chronic infection, inflammation, and epithelial ovarian cancer. Medical hypotheses, V.57, N.4, pp.426-428, ISSN: 0306-9877.

Rich, E., Hook, E.W.III, Alarcon, G.S., \& Moreland, L.W. (1996) Reactive arthritis in patients attending an urban sexually transmitted diseases clinic. Arthritis and rheumatism, V.39, N.7, pp.1172-1177, ISSN: 0004-3591.

Robman, L., Mahdi, O., McCarty, C., Dimitrov, P., Tikellis, G., McNeill, J., Bryne, G., Taylor, H., \& Guymer, R. (2005) Exposure to Chlamydia pneumoniae infection and progression of age-related macular degeneration. American journal of epidemiology, V.161, N.11, pp.1013-1019, ISSN: 0002-9262.

Saikku, P., Leinonen, M., Mattila, K., Ekman, M.R., Nieminen, M.S., Makela, P.H., Huttunen, J.K., \& Valtonen, V. (1988) Serological evidence of an association of a novel Chlamydia TWAR, with chronic heart disease and acute myocardial infarction. Lancet, V.2, N.8618, pp.983-986, ISSN: 0140-6736.

Samaras, V., Rafailidis, P.I., Mourtzoukou, E.G., Peppas, G., \& Falagas, M.E. (2010) Chronic bacterial and parasitic infections and cancer: a review. Journal of infection in developing countries, V.4, N.5, pp.267-281, ISSN: 2036-6590.

Siveira, L.H., Gutierrez, F., Scopelitis, E., Cuellar, M.L., Citera, G., \& Espinoza, L.R. (1993) Chlamydia-induced arthritis. Rheumatic diseases clinics of North America, V.19, N.2, pp.351-363, ISSN: 0889-857X.

Sriram, S., Ljunggren-Rose, A., Yao, S-Y., \& Whetsell, Jr W.O. (2005) Detection of chlamydial bodies and antigens in the central nervous system of patients with multiple sclerosis. The Journal of infectious diseases, V.192, N.7, pp.1219-1228, ISSN: 0022-1899.

Stassen, F.R., Vainas, T., \& Bruggeman, C.A. (2008) Infection and atherosclerosis. An alternative view of an outdated hypothesis. Pharmacological reports, V.60, N.1, pp.8592, ISSN: 1734-1140.

Stratton, C.W., \& Sriram, S. (2003) Association of Chlamydia pneumoniae with central nervous system disease. Microbes and infection, V.5, N.13, pp.1249-1253, ISSN: 1286-4579.

Stratton, C.W., \& Wheldon, D.B. (2007) Antimicrobial treatment of multipl sclerosis. Infection, V.35, N.5, pp.383-385, ISSN: 0300-8126.

Sutherland, E.R., Brandiorff, J.M., \& Martin, J.M. (2004) Atypical bacterial pneumonia and asthma risk. The Journal of asthma, V.41, N.8, pp.863-868, ISSN: 0277-0903.

Sziller, I., Fedorcsak, P., Csapo, Z., Szirmal, K., Linhares, I.M., Papp, Z., \& Witkin, S.S. (2008) Cirulating antibodies to a conserved epitope of the Chlamydia trachomatis $60-\mathrm{kDa}$ 
heat shock protein is associated with decreased spontaneous fertility rate in ectopic pregnant women treated by salpingectomy. American journal of reproductive immunology, V.59, N.2, pp. 99-104, ISSN:1046-7408.

Tositti, G., Rassu, M., Fabris, P., Giordani, M., Cazzavillan, S., Reatto, P., Zoppelletto, M., Bonoldi, M., Baldo, V., Manfrin, V., \& de Lalla, F. (2005) Chlamyida pneumoniae infection in HIV-positive patients: prevalence and relationship with lipid profile. HIV Medicine, V.6, N.1, pp.27-32, ISSN: 1464-2662.

Trojian, T.H., Lishnak, T.S., \& Heiman, D. (2009) Epididymitis and orchitis: an overwiev. American family physician, V.79, N.7, pp.583-587, ISSN: 0002-838X.

Vink, A., Poppen, M., Schoneveld, A.H., Roholl, P.J., de Kleijn, D.P., Borst, C., \& Pasterkamp, G. (2001) Distribution of Chlamydia pneumoniae in the human arterial system and its relation to the local amount of atherosclerosis within the individual. Circulation; V.103, N.12, pp.1613-1617, ISSN: 0009-7322.

Voorend, M., Aan der Ven, A.J.A.M., Kubat, B., Lodder, J., \& Bruggeman, C.A. (2008) Limited role for C. pneumoniae, CMV, and HSV1 in cerebral large and small vessel atherosclerosis. The open neurology journal, V.2, pp.39-44, ISSN: 1874205X.

Wang, C., Gao, D., \& Kaltenboeck, B. (2009) Acute Chlamydia pneumoniae reinfection accelerates the development of insulin resistance and diabetes in obese C57BL/6 mice. The Journal of infectious diseases, V.200, N.2, pp.279-287, ISSN: 0022-1899.

Ward, M.E. (1995) The immunology and immunopathology of chlamydial infections. Acta pathologica, microbiologica, et immunologica Scandinavica, V.103, N.11, pp.769-796, ISSN: 0903-4641.

Wark, P.A.B., Johnston, S.L., Simpson, J.L., Hensley, M.J., \& Gibson, P.G. (2002) Chlamydia pneumoniae immunoglobulin A reactivation and airway inflammation in acute asthma. The European respiratory journal, V.20, N.4, pp.834-840, ISSN: 0903-1936.

Webley, W.C., Savla, P.S., Andrejewsk, C., Cirino, F., West, C.A., Tilahun, Y., \& Stuart, E.S. (2005) The bronchial lavage of pediatric patients with asthma contains infectious chlamydia. American journal of respiratory and critical care medicine, V.171, N:10, pp.1083-1088, ISSN: 1073-449X.

Webley, W.C., Tilahun, Y., Lay, K., Patel, K., Stuart, E.S., Andrzejewski, C., \& Salva, P.S. (2009) Occurrence of Chlamydia trachomatis and Chlamydia pneumonia in paediatric respiratory infections. The European respiratory journal, V.33, N.2, pp.360367, ISSN: 0903-1936.

Wetmore, C.M., Manhart, L.E., \& Golden, M.R. (2009) Idiopathic urethritis in young men in the United States: prevanelnce and comparison to infections with known sexually transmitted pathogens. The Journal of adolescent health, V.45, N.5, pp.463-472, ISSN: 1054-139X.

Wright, H.R., Turner, A., \& Taylor, H.R. (2007) Trachoma. Lancet, V.371, N.9628, pp.19451954, ISSN: 0140-6736. 
Wu, S., Shen, L., \& Liu, G. (1999) Study on vertical transmission of Chlamydia trachomatis using PCR and DNA sequencing. Chinese medical journal, V.112, N.5, pp.396-399, ISSN: 0366-6999.

Yakushijin, Y., Kodama, T., Takaoka, I., Tanimoto, K., Bessho, H., Sakai, I., Hato, T., Hasegawa, H., \& Yasukawa, M. (2007) Absence of chlamydial infection in Japanese patients with ocular adnexal lymphoma of mucosa-associated lymphoid tissue. International journal of hematology, V.85, N.3, pp.223-230, ISSN:0925-5710.

Yucesan, C., \& Sriram, S. (2001) Chlamydia pneumoniae infection of the central nervous system. Current opinion in neurology, V.14, N.3, pp.355-359, ISSN: 1350-7540. 


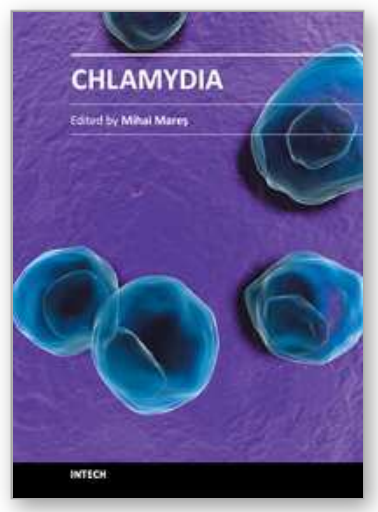

\author{
Chlamydia \\ Edited by Prof. Mihai Mares
}

ISBN 978-953-51-0470-4

Hard cover, 358 pages

Publisher Intech

Published online 30, March, 2012

Published in print edition March, 2012

Nowadays, Chlamydia still represents a redoubtable pathogen. Among its consequences, the blindness in children and severe impairment of reproductive health in adults are the most mutilating. Worldwide, it is estimated that six million of people suffer from post-trachoma blindness and almost 90 million become sexually infected each year. Due to its silent evolution and sexually transmission, the chlamydial infection can occur in anyone. The book "Chlamydia - A Multifaceted Pathogen" contains an updated review of all-important issues concerning the chlamydial infection. It comprises 18 chapters grouped in four major parts dealing with etiology and pathogenicity, clinical aspects, diagnosis and prevention. The new molecular data about the pathogenicity and the exhaustive presentation of clinical findings bring novelty to the book and improve our knowledge about Chlamydia induced diseases.

\title{
How to reference
}

In order to correctly reference this scholarly work, feel free to copy and paste the following:

Teoman Zafer Apan (2012). Chlamydia: Possible Mechanisms of the Long Term Complications, Chlamydia, Prof. Mihai Mares (Ed.), ISBN: 978-953-51-0470-4, InTech, Available from: http://www.intechopen.com/books/chlamydia/chlamydia-long-term-complications-and-related-disorders

\section{INTECH}

open science | open minds

\section{InTech Europe}

University Campus STeP Ri Slavka Krautzeka 83/A 51000 Rijeka, Croatia Phone: +385 (51) 770447 Fax: +385 (51) 686166 www.intechopen.com

\section{InTech China}

Unit 405, Office Block, Hotel Equatorial Shanghai No.65, Yan An Road (West), Shanghai, 200040, China 中国上海市延安西路65号上海国际贵都大饭店办公楼405单元 Phone: +86-21-62489820

Fax: $+86-21-62489821$ 
(C) 2012 The Author(s). Licensee IntechOpen. This is an open access article distributed under the terms of the Creative Commons Attribution 3.0 License, which permits unrestricted use, distribution, and reproduction in any medium, provided the original work is properly cited. 